\title{
Role of tranexamic acid in endoscopic sinus surgery - A systematic review and meta-analysis*
}

\author{
Vishal Pundir', Jyotsna Pundir², Christos Georgalas ${ }^{3}$, W.J. Fokkens \\ 'Department of Otorhinolaryngology, East Sussex Healthcare NHS Trust, Conquest Hospital, United Kingdom \\ 2 Department of Obstetrics and Gynaecology, Maidstone and Tunbridge Wells NHS Trust, United Kingdom \\ ${ }^{3}$ Ear Nose and Throat Department, Academic Medical Centre, Amsterdam, the Netherlands
}

Rhinology 51: 291-297, 2013

DOl:10.4193/Rhino13.042

*Received for publication:

April 17, 2013

Accepted: July 10, 2013

\section{Summary}

Background: The role of tranexamic acid in patients undergoing endoscopic sinus surgery (ESS) is not clearly defined. The aim of our study is to systematically review the existing evidence on the role of tranexamic acid in patients undergoing ESS.

Methodology: Systematic search of MEDLINE (1950 - 2013), EMBASE (1980 - 2013), metaRegister, Cochrane Library and ISI conference proceedings was carried out.

Results: Five randomised controlled trials with 192 patients receiving tranexamic acid and 196 controls were included. Metaanalysis demonstrated that mean estimated blood loss was significantly lower, and surgical field quality was significantly better in tranexamic acid group. There was no significant difference in mean operative time between the two groups. No significant adverse effects were noted in either of the groups.

Conclusion: Intra-operative use of local and systemic tranexamic acid in ESS, results in significantly reduced estimated blood loss and improved surgical field quality. There is no statistically significant difference seen in operative time and incidence of side effects. Well-conducted larger RCTs using validated objective outcome measures and reporting on minor and major complications are required.

Key words: endoscopic sinus surgery, tranaexamic acid, blood loss, surgical field

\section{Introduction}

Endoscopic sinus surgery (ESS) was first described by Stammberger ${ }^{(1)}$ in 1985 and Kennedy ${ }^{(2)}$ coined the term functional endoscopic sinus surgery (FESS) to highlight its surgical philosophy of mucosal sparing. With improvement in the knowledge of the anatomy of the sinus system, advances in image guided surgery and development of specialized instruments, ESS has developed into a safe and effective treatment option for many conditions and is one of the commonest procedures performed ${ }^{(3,4)}$. Endoscopic lacrimal surgery ${ }^{(5)}$, orbital decompression ${ }^{(6)}$, benign and malignant endonasal tumour removal ${ }^{(7-9)}$ and more recently endoscopic transnasal intracranial surgery have all been a great extension to the basic technique of ESS.

In spite of all the advances, peri-operative bleeding in ESS still remains a challenge as it occurs in up to $5 \%$ of cases ${ }^{(10)}$. Intraoperative bleeding makes recognition of anatomical landmarks difficult and obscures surgical planes. Bleeding results in difficulty in differentiation between cell walls and critical anatomical structures like lamina paprycea and skull base leading to increased risk of complications, prolonged operative time and sometimes resulting in incomplete surgery ${ }^{(11)}$. Several interventions like positioning of patient, use of topical vasoconstrictive agents, preoperative antibiotics and steroids, bipolar cautery, infiltration of pterygopalatine fossa have been used in an at- 
tempt to reduce intra-operative bleeding ${ }^{(11)}$. These have been supplemented with the use of hypotensive anaesthetic agents and techniques like total intravenous anaesthesia (TIVA) ${ }^{(12)}$.

Antifibrinolytic agents were first described in $1964^{(13)}$ and have been used widely in variety of clinical settings since then. Two synthetic derivatives of the amino acid lysine, tranexamic acid [4-(aminomethyl)cyclohexanecarboxylic acid] and eaminocaproic acid (EACA; 6-aminohexanoic acid) have shown antifibrinolytic activity in humans ${ }^{(14)}$. Both of these agents bind to lysine binding site of plasminogen thereby inhibiting the interaction of plasminogen and fibrin thus preventing fibrinolysis and stabilizing the blood clot thereby reduces overall bleeding (13). Fibrinolytic test systems comparing the binding potencies of tranexamic acid and EACA have shown tranexamic acid to be more potent by a factor of between 6 and $10(13,15,16)$. These agents have been used in patients with bleeding disorders and to reduce intra-operative bleeding during various surgical procedures ${ }^{(14)}$.They are now widely used in head and neck surgery including oral surgery, parotid surgery, and tonsillectomy ${ }^{(17-20)}$. There are few studies evaluating the role of tranexamic in ESS, however, these studies have reported conflicting results.

The aim of our study is to systematically review the existing evidence on the role of tranexamic acid in patients undergoing ESS. The intention of our systematic review and meta-analysis is to determine whether intra-operative tranexamic acid affect operative parameters i.e. estimated blood loss, surgical field quality and operative time.

\section{Materials and methods}

Data sources and literature search

We conducted systematic searches for randomised controlled trials (RCTs). There were no language, publication year or publication status restrictions. The date of the last search was January 1. 2013. We searched MEDLINE, EMBASE, metaRegister, Cochrane Library and ISI conference proceedings. A combination of $\mathrm{MeSH}$ and text words were used to generate two subsets of citations, one including studies of endoscopic surgery ('endoscopic sinus surgery', 'sinus surgery,' 'FESS', 'functional endoscopic sinus surgery,',nasal surgery') and the second including tranexamic acid ('tranexamic acid,' 'antifibrinolytics", 'cyclokapron,' 'lysteda', 'transmin ','trascam ', 'espercil','traxyl,' 'Cyclo-F ,'Femstrual '.). These subsets were combined using 'AND' to generate a subset of citations relevant to our research question. The reference lists of all known primary and review articles were hand searched to identify cited articles not captured by electronic searches. The searches were conducted independently by VP and JP.

\section{Study selection}

Two review authors (VP and JP) performed data selection and extraction based on predetermined criteria. Studies were selected in a two-stage process. Firstly, the titles and abstracts from the electronic searches were scrutinized and full manuscripts of all citations that were likely to meet the predefined selection criteria were obtained. Final inclusion or exclusion decisions were made on examination of the full manuscripts. In cases of duplicate publication, the most recent or complete versions were selected. We documented our justification for the exclusion of studies.

\section{Data extraction}

Two reviewers (JP and VP) completed data extraction. Study characteristics and participant features were extracted from each study regarding: characteristics of trials - setting, design, method of data analysis; participants - study population, number of participants; type of intervention: dose, route of administration, duration of treatment, follow-up and outcomes. Inconsistencies between reviewer's data were resolved through discussion with other reviewers until a consensus was reached. After identifying the studies where additional data were needed, a request was sent by means of electronic mail to the corresponding author of each study.

\section{Data Synthesis \\ Inclusion and exclusion criteria}

Studies were selected if the target population underwent endoscopic sinus surgery, and were exposed to tranexamic acid and compared with either placebo or no tranexamic acid. Only RCTs were included. Trials including participants of any age, who had any co-morbidity including asthma and aspirin sensitivity, allergic or non-allergic, followed for any duration, CRS with and without polyps were included. Studies were included irrespective of the dose, duration or route of administration of tranexamic acid.

\section{Outcomes assessed}

The main outcomes assessed were estimated blood loss (EBL), surgical field quality and operative time. We also assessed possible adverse effects of the medication.

\section{Assessment of risk of bias in included studies}

We assessed the methodological quality of the included studies and carried out the assessment of risk of bias ${ }^{(21)}$, taking into consideration: method of randomisation; allocation concealment; blinding; incomplete outcome data; selective outcome reporting; and other sources of bias. We used the Cochrane 'Risk of bias' tool in RevMan 5.1 ${ }^{(22)}$, which involved describing each of these domains as reported in the trial and then assigning a judgement about the adequacy of each entry as low, high or unclear risk of bias. We presented this information in a'risk of bias' graph and summary. 


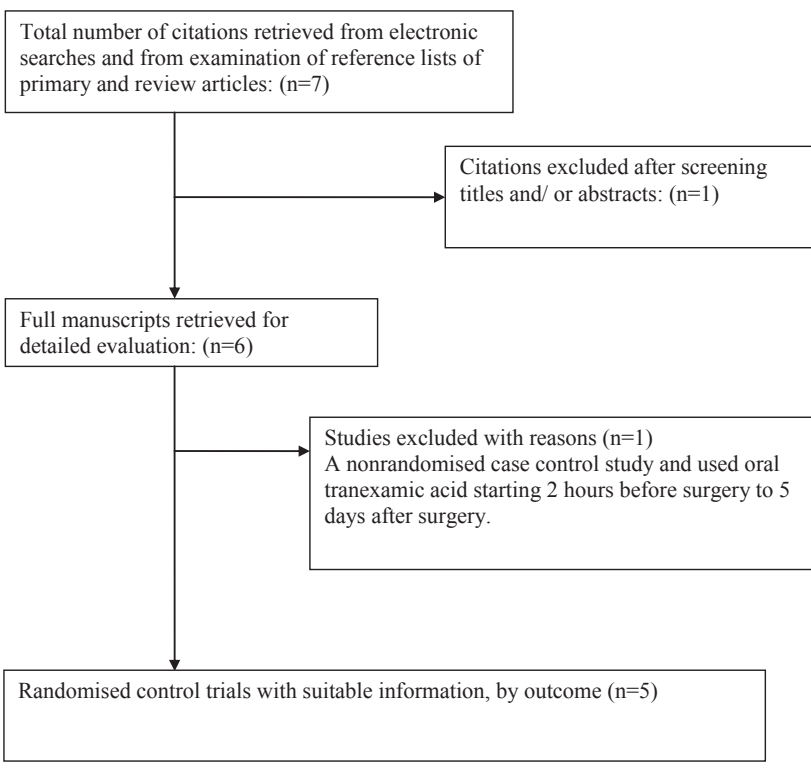

Figure1. Consort diagram - Study selection process for the systematic review of role of tranexamic acid in endoscopic sinus surgery.

\section{Statistical analyses}

Meta-analysis was performed in line with recommendations from the Cochrane Collaboration and the Quality of Reporting of Meta-analyses (QUORUM) guidelines ${ }^{(23,24)}$. From each study, dichotomous outcome data were summarised in $2 \times 2$ tables by two reviewers (VP, JP). The results were pooled and expressed as risk ratios (RR). Continuous variables were analyzed using weighted mean differences (WMD) or standardised mean differences (SMD) ${ }^{(25)}$, with 95\% confidence intervals (Cls). The results were pooled using either a fixed effect ${ }^{(26)}$ or random effect model as appropriate ${ }^{(25)}$. Heterogeneity of the exposure effects was evaluated statistically using the 12 statistic to quantify heterogeneity across studies ${ }^{(27)}$. A I 2 value of $>50 \%$ was taken as evidence of substantial heterogeneity and in such cases a random effect model was used. A chi-squared test for heterogeneity was also performed and the ' $p$ ' values are presented.

When a study failed to present a standard deviation (SD), this statistic was either calculated from standard error of mean, 95\% $\mathrm{Cl}$, $\mathrm{t}$ value or interquartile range ${ }^{(28)}$. Some studies provide only ranges, in such instances, the SD was estimated using the formula total range/4 ${ }^{(29)}$. Statistical analyses were performed using RevMan 5 software.

\section{Results}

\section{Study selection}

Of the 7 citations identified by the search, 6 were selected after initial screening as the seventh compared two doses of tranexamic acid ${ }^{(30)}$. Following examination of the full manuscripts of these six studies, one study was excluded as it was a nonrandomised case control study and used oral tranexamic acid starting

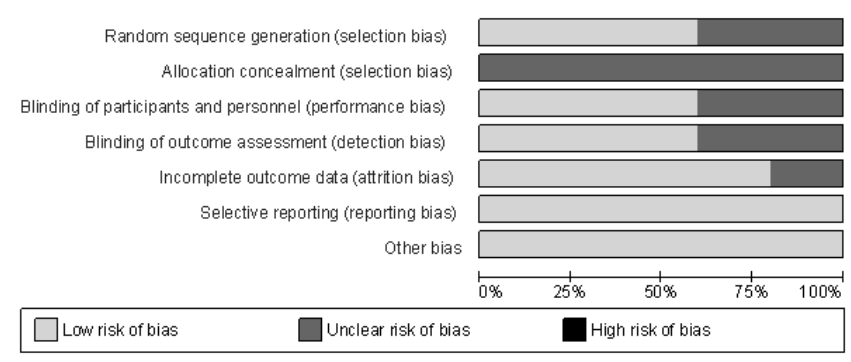

Figure 2. 'Risk of bias' graph: for the systematic review -role of tranexamic acid in endoscopic sinus surgery - each risk of bias item presented as percentages across all included studies.

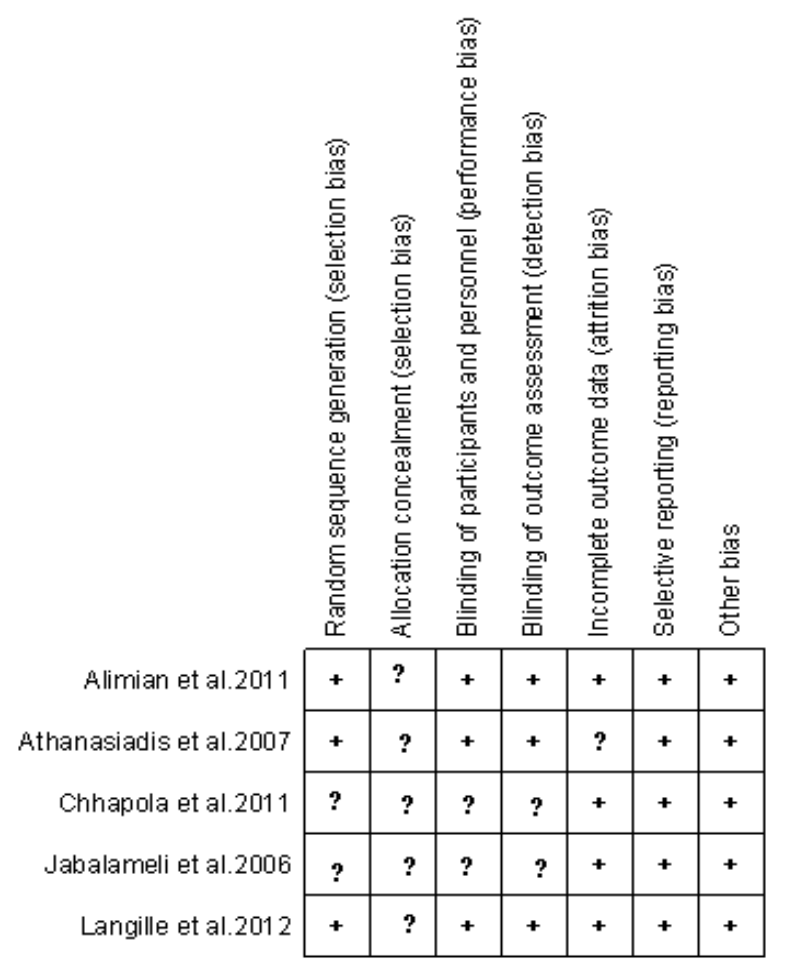

Figure 3. 'Risk of bias' summary: For the systematic review - Role of tranexamic acid in endoscopic sinus surgery - Each risk of bias item for each included study.

2 hours before surgery to 5 days after surgery ${ }^{(31)}$.

Five studies satisfied the selection criteria and were included in this review ${ }^{(32-36)}$, comprising of 192 patients receiving tranexamic acid and 196 controls (Figure 1). Sample size per study varied across the trials and ranged from 10 to 100 participants. Intra-operative tranexamic acid was either used intravenously ${ }^{(32,34,36)}$ or topically ${ }^{(33,35)}$. In our attempt to get more information about studies with unpublished data, we received response from Chhapola et.al ${ }^{(34)}$.

\section{Study characteristics}

A description of included studies is summarised in Table 1. Risk 
Table 1. Characteristics of the studies included in the review-tranexamic acid in endoscopic sinus surgery.

\begin{tabular}{|c|c|c|c|c|c|c|}
\hline $\begin{array}{c}\text { Author/ cases and } \\
\text { controls }\end{array}$ & Inclusion Criteria & Exclusion Criteria & Cases Protocol & Control Protocol & Follow-up & Outcomes \\
\hline $\begin{array}{l}\text { Alimian et al. }{ }^{(32)} \\
2011 \\
\text { Cases-42 } \\
\text { Contols-42 }\end{array}$ & $\begin{array}{l}\text { Patient undergoing } \\
\text { Endoscopic Sinus } \\
\text { Surgery with ASA } \\
\text { Grade I and II, Age } \\
\text { 19-64 years }\end{array}$ & $\begin{array}{l}\text { Patients on antico- } \\
\text { agulants or having } \\
\text { bleeding diasthesis }\end{array}$ & $\begin{array}{l}\text { tranexamic } \\
\text { acid } 10 \mathrm{mg} / \mathrm{kg} \\
\text { of IV bolus dose } \\
\text { immediately after } \\
\text { induction } \\
\text { of anesthesia. }\end{array}$ & $\begin{array}{l}\text { sterile water } 0.1 \\
\mathrm{~mL} / \mathrm{kg} \\
\text { as a bolus dose } \\
\text { immediately after } \\
\text { induction } \\
\text { of anesthesia }\end{array}$ & $100 \%$ & $\begin{array}{l}\text { Intraoperative blood loss } \\
\text { Boezart intraoperative } \\
\text { surgical field score } \\
\text { Prothrombin } \\
\text { time, partial thromboplas- } \\
\text { tin time, and complete } \\
\text { blood count } \\
\text { were measured before } \\
\text { surgery and } 6 \text { hours post- } \\
\text { operatively. }\end{array}$ \\
\hline $\begin{array}{l}\text { Athanasiadis et al. }{ }^{(33)} \\
2007 \\
\text { Cases-10 } \\
\text { Contols-10 }\end{array}$ & $\begin{array}{l}\text { Patient undergoing } \\
\text { Endoscopic Sinus } \\
\text { Surgery }>18 \text { yrs } \\
\text { age }\end{array}$ & $\begin{array}{l}\text { Asymmetric } \\
\text { disease and were } \\
\text { not receiving } \\
\text { similar surgery on } \\
\text { both sides. } \\
\text { Allergies to antifi- } \\
\text { brinolytics. } \\
\text { Pregnancy or } \\
\text { breast feeding } \\
\text { On anticoagulants } \\
\text { or having bleeding } \\
\text { diathesis }\end{array}$ & $\begin{array}{l}\text { tranexamic acid } \\
100 \mathrm{mg} \text { topically }\end{array}$ & Normal Saline & $100 \%$ & Surgical field score \\
\hline $\begin{array}{l}\text { Chhapola et al. }{ }^{(34)} \\
2011 \\
\text { Cases-100 } \\
\text { Contols-100 }\end{array}$ & $\begin{array}{l}\text { Patient undergoing } \\
\text { Endoscopic Sinus } \\
\text { Surgery } \\
\text { (FESS, Excision of } \\
\text { nasal mass, Septo- } \\
\text { plasty) }\end{array}$ & Not Mentioned & $\begin{array}{l}\text { Tranaexamic Acid } \\
\text { infusion }(500 \mathrm{mg} \text { in } \\
100 \mathrm{ml} \text { normal sa- } \\
\text { line) } 20-30 \text { minutes } \\
\text { preoperatively }\end{array}$ & $\begin{array}{l}\text { Did not receive } \\
\text { tranexamic acid }\end{array}$ & $100 \%$ & Intraoperative blood loss \\
\hline $\begin{array}{l}\text { Jabalameli et al. }{ }^{(35)} \\
2006 \\
\text { Cases-26 } \\
\text { Contols-30 }\end{array}$ & $\begin{array}{l}\text { Patient undergoing } \\
\text { Endoscopic Sinus } \\
\text { Surgery with ASA } \\
\text { Grade I and II }\end{array}$ & $\begin{array}{l}\text { On medications af- } \\
\text { fecting coagulation } \\
\text { system. } \\
\text { History of throm- } \\
\text { boembolic events, } \\
\text { disseminated intra- } \\
\text { vascular coagulo- } \\
\text { pathy, hemophilia, } \\
\text { hypersensitivity to } \\
\text { drugs and abnor- } \\
\text { mal renal function. }\end{array}$ & $\begin{array}{l}\text { Tranexamic acid } \\
\text { (1000 mg diluted } \\
\text { in } 20 \mathrm{ml} \text { normal } \\
\text { saline) } \\
\text { administered } \\
\text { topically }\end{array}$ & $\begin{array}{l}\text { same volume of } \\
\text { normal } \\
\text { saline was adminis- } \\
\text { tered topically }\end{array}$ & $100 \%$ & $\begin{array}{l}\text { Intraoperative blood loss } \\
\text { Boezart intraoperative } \\
\text { surgical field score }\end{array}$ \\
\hline $\begin{array}{l}\text { Langille et al. }{ }^{(36)} \\
2012 \\
\text { Cases-14 } \\
\text { Contols-14 }\end{array}$ & $\begin{array}{l}\text { Patient With CRS } \\
\text { and CRSwNP who } \\
\text { failed medical } \\
\text { treatment under- } \\
\text { going Endoscopic } \\
\text { Sinus Surgery }\end{array}$ & $\begin{array}{l}\text { History of hyper- } \\
\text { tension, renal } \\
\text { failure, vascular } \\
\text { disease, ASA Grade } \\
\text { III or higher, under- } \\
\text { going any other } \\
\text { procedure like } \\
\text { Septoplasty }\end{array}$ & $\begin{array}{l}\text { Tranexamic acid } \\
\text { bolus ( } 15 \mathrm{mg} / \\
\mathrm{kg}) \text { followed by } \\
\text { infusion }(1 \mathrm{mg} / \mathrm{kg} / \\
\mathrm{hr}) \text { throughout the } \\
\text { operation }\end{array}$ & $\begin{array}{l}\text { Equivalent amount } \\
\text { of normal saline }\end{array}$ & $100 \%$ & $\begin{array}{l}\text { Intraoperative blood loss } \\
\text { Wormald intraoperative } \\
\text { surgical field score } \\
\text { POSE Score, LKES Score }\end{array}$ \\
\hline
\end{tabular}

of bias from included studies is represented in Figures 2 and 3. Our judgements about each risk of bias item, presented as percentages across all included studies, are shown in Figure 2, and for each risk of bias item for each included study in Figure 3. Generally, included studies had medium risk of bias for method of randomisation and blinding, low risk of bias for incomplete outcome data and selective reporting and unclear risk of bias for allocation concealment.

\section{Outcomes}

Estimated blood loss (EBL)

Data addressing this comparison were available from four studies ${ }^{(32,34-36)}$. Pooling of the results showed that, mean EBL was significantly lower in the tranexamic acid group compared to the no tranexamic acid group (WMD $-104.10 \mathrm{mls} ; 95 \% \mathrm{Cl}$ $-185.60,-22.60 ; p=0.01$; Figure 4). 12 was $99 \%$, suggesting significant heterogeneity. 


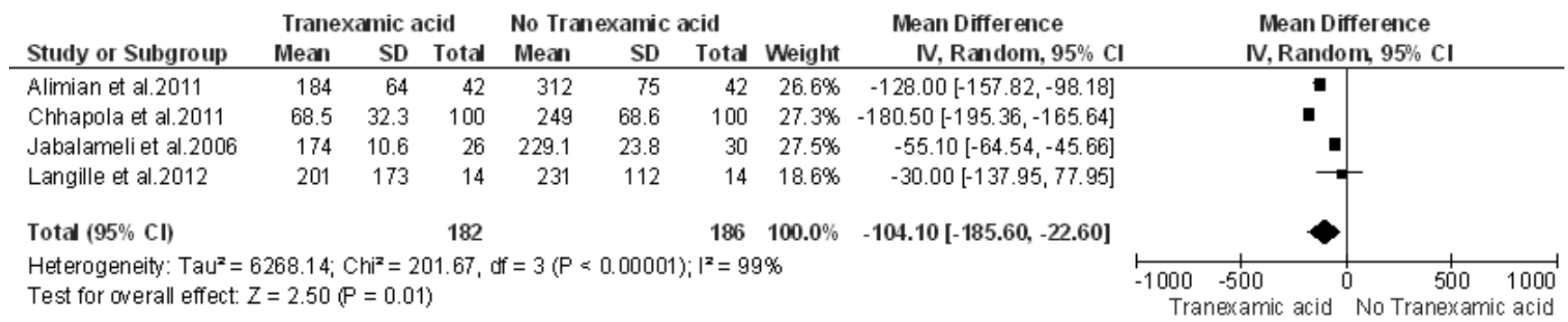

Figure 4. Forest plot of comparison - estimated blood loss-tranexamic acid vs no tranexamic acid.

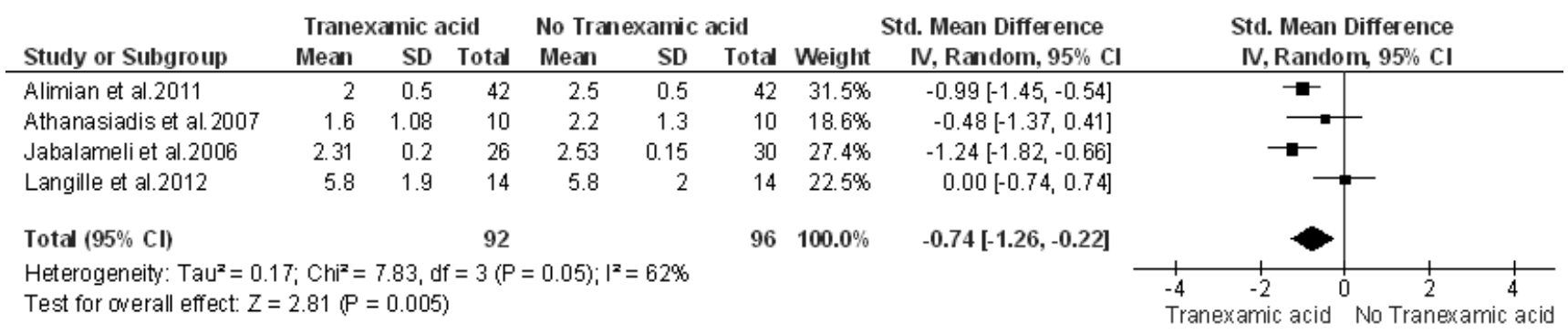

Figure 5. Forest plot of comparison -surgical field quality score-tranexamic acid vs no tranexamic acid.

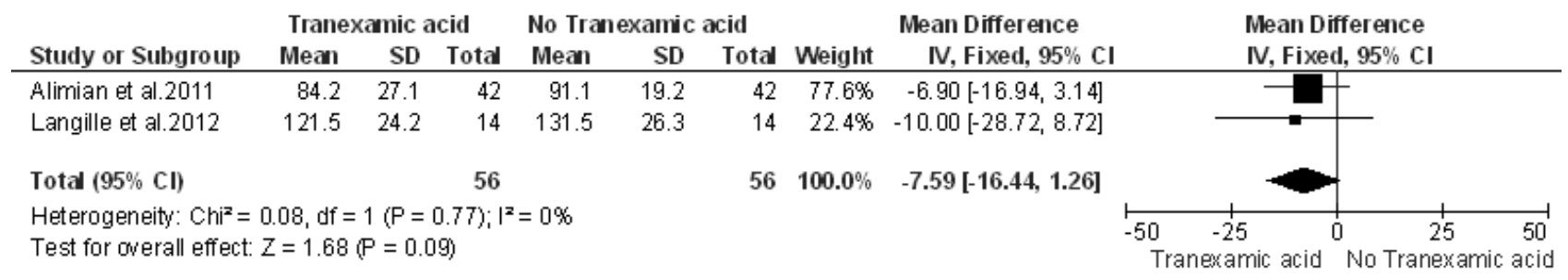

Figure 6. Forest plot of comparison -operative time -tranexamic acid vs no tranexamic acid.

\section{Surgical field quality}

The surgical field quality was reported on two different scoring system, the Boezaart system ${ }^{(37)}$ by Alimian et al. ${ }^{(32)}$, Athanasiadis et al. ${ }^{(33)}$ and Jabalameli et al. ${ }^{(35)}$, and the Wormald system ${ }^{(33)}$ by Langille et al. ${ }^{(36)}$. We used standardised mean difference as a summary statistic for this outcome because the included studies assessed the same outcome but measured it in a variety of ways, to standardise the results of the studies to a uniform scale before they could be combined.

Data addressing this comparison were available from four studies ${ }^{(32,33,35,36)}$. Pooling of the results of these showed that, surgical field quality was significantly better in tranexamic acid group as compared to no tranexamic acid group (SMD $-0.74 ; 95 \% \mathrm{Cl}-1.26$, $-0.22 ; p=0.005$; Figure 5). 12 was $62 \%$, suggesting significant heterogeneity.

\section{Operating time}

Data addressing this comparison were available from two studies ${ }^{(32,36)}$. Pooling the results showed that mean operative time was not significantly different in the tranexamic acid group compared to the no tranexamic acid group (WMD -7.59 minutes; $95 \% \mathrm{Cl}-16.44,1.26 ; \mathrm{p}=0.09$; Figure 6 ). 12 was $0 \%$, suggesting no significant heterogeneity.

\section{Adverse effects}

Pooled data for postoperative bleeding showed no bleeding out of 66 cases, and one case of bleeding out of 66 controls ${ }^{(32,33,36)}$.

Pooled data for post operative nausea or vomiting showed 6 patients out of 56 suffered with nausea and vomiting in tranexamic acid group compared to 4 out of 56 patients in the control group $^{(32,36)}$. None of the studies reported serious thromboembolic event in any patients both in tranexamic acid and controls. 


\section{Discussion}

Our systematic review and meta-analysis of randomised controlled trials demonstrated that estimated blood loss was significantly lower, and surgical field quality was significantly better in the tranexamic acid group compared to the non tranexamic acid group in patients undergoing ESS. In relation to operating time in response to intra-operative tranexamic acid there was no significant difference, however, there is a trend of benefit towards the use of tranexamic acid. The use of tranexamic acid was not associated with any significant increased risk of post operative nausea, vomiting, bleeding or thromboembolic complications. The reduction in estimated blood loss with the use of tranexamic acid as shown in our systematic review is in accordance with other reports of reduction in intra-operative bleeding seen in other procedures. A recent systematic review on the use of tranexamic acid in tonsillectomy, including two RCTs has reported similar reduction in EBL ${ }^{(19)}$. As expected the reduction in $\mathrm{EBL}$ in our systematic review has also showed a significant improvement in surgical field quality.

Regarding the operating time, even though it did not reach statistical significance, there is a trend toward the benefit with the use of tranexamic acid. This statistical insignificance could be most likely due to the small sample size in this review, as only two RCTs including 102 patients reported on this outcome.

The main side effects associated with tranexamic acid, though uncommon, are nausea, diarrhoea and orthostatic reactions ${ }^{(14)}$. Our review showed no significant difference in the occurrence of nausea and vomiting in the patients taking tranexamic acid compared to placebo. There is also theoretical risk of increased thrombotic tendency with some case reports of cerebral thrombosis ${ }^{(38,39)}$, arterial thrombosis ${ }^{(40)}$, acute renal failure ${ }^{(41,42)}$ being reported. However, none of the studies included in our systematic review reported on any thromboembolic event out of total population of sample of 192 patients using tranexamic acid. Long-term follow-up data on these patients was not available, however, the remote thromboembolism secondary to intraoperative single dose of tranexamic acid seems unlikely as it has a short halflife ${ }^{(14)}$. This observation is in accordance with other controlled studies; including several randomised studies in patients undergoing cardiac surgery ${ }^{(43-46)}$. Furthermore, no thromboembolic episode was reported in a retrospective analysis of 256 pregnant women with bleeding disorders who were on tranexamic acid ${ }^{(47)}$. These findings are particularly reassuring, because pregnant women are at an increased risk of throm- bosis especially after caesarian section, as about two third of these women underwent caesarean section, but none of them developed any thromboebolic event. However, this should be interpreted with caution as the numbers are not high enough, unlike efficacy, where smaller numbers are adequate, safety can only be assessed in much bigger studies.

\section{Limitations of the review}

Limitations of our systematic review include potential biases in the review process regarding the eligibility criteria and data analyses. The majority of these studies were limited to small sample size and adopted different endoscopic scores. Only 5 randomized studies were included and that the medication was applied topically in two studies and was applied systemically in the other three studies. Clinical diversity, including variability in dose, route, duration and the delivery methods, led to heterogeneity in the studies included in this review. Our review, even though it had significant heterogeneity in some outcomes, has attempted to bring the existing evidence together and represents the best evidence on this subject available.

\section{Concluding remarks}

Intra-operative use of local and systemic tranexamic acid in ESS, results in significantly reduced estimated blood loss and improved surgical field quality. There is no statistically significant difference seen in operative time and incidence of side effects. There was no incidence of serious side effects of thromboembolism in the included studies. Well-conducted longer term and larger RCTs are required using, standardised inclusion criteria; specified dose, duration and route of tranexamic acid; validated objective outcome measures and reporting on minor and major complications.

\section{Acknowledgements}

This study was not supported by any company or persons other than the authors.

\section{Authorship contribution}

VP: Conception, planning, literature search, data extraction, analysing and writing up. JP: Literature search, data extraction, analysing data. CG and WJF: Writing up and editing the draft.

\section{Conflict of interest}

None to declare.

\section{References}

1. Stammberger $\mathrm{H}$. Endoscopic surgery for mycotic and chronic recurring sinusitis. Ann Otol Rhinol Laryngol.1985; 94 (suppl 119): 1-11.

2. Kennedy D.W. Functional endoscopic sinus surgery: technique. Arch Otolaryngol. 1985
111: 643-649.

3. Fokkens WJ, Lund VJ, Mullol J et al. EPOS 2012: European position paper on rhinosinusitis and nasal polyps 2012. Rhinology supplement 2012; 23: 1-298.

4. Poetker DM, Smith TL. Adult chronic rhinosinusitis: surgical outcomes and the role of endoscopic sinus surgery. Curr Opin Otolaryngol Head Neck Surg. 2007; 15: 6-9.

5. Wormald PJ. Powered endoscopic dacryocystorhinostomy. Laryngoscope. 2002; 112: 69-72.

6. Wee DT, Carney AS, Thorpe M, Wormald PJ. Endoscopic orbital decompression for 
Graves' ophthalmopathy. J Laryngol Otol. 2002; 116: 6-9.

7. Wormald PJ, Ooi E, van Hasselt CA, Nair S. Endoscopic removal of sinonasal inverted papilloma including endoscopic medial maxillectomy. Laryngoscope. 2003; 113: 867-873.

8. Wormald PJ, Van Hasselt A. Endoscopic removal of juvenile angiofibromas. Otolaryngol Head Neck Surg. 2003; 129: 684-691.

9. Knegt PP, Ah-See KW, vd Velden LA, Kerrebijn J. Adenocarcinoma of the ethmoidal sinus complex: surgical debulking and topical fluorouracil may be the optimal treatment. Arch Otolaryngol Head Neck Surg. 2001; 127: 141-146.

10. Hopkins C, Browne JP, Slack R Complications of surgery for nasal polyposis and chronic rhinosinusitis: the results of a national audit in England and Wales. Laryngoscope. 2006; 116: 1494-1499.

11. Wormald PJ. In Endoscopic Sinus Surgery - Anatomy, Three Dimensional Reconstruction, and Surgical Technique. New York: Thieme, 2005.

12. Wormald PJ, van Renen G, Perks J, Jones JA, Langton-Hewer CD. The effect of the total intravenous anesthesia compared with inhalational anesthesia on the surgical field during endoscopic sinus surgery. Am J Rhinol. 2005; 19: 514-520.

13. Okamoto S, Sato S, Takada Y, Okamoto U. An active stereo isomer (trans-form) of AMCHA and its fibrinolytic (antiplasminic) action in vitro and in vivo. Keio J Med. 1964; 13: 177-185.

14. Dunn CJ, Goa KL. Tranexamic acid: a review of its use in surgery and other indications. Drugs. 1999; 57: 1005-1032.

15. Andersson L, Nilsson IM, Niléhn JE, Hedner U, Granstrand B, Melander B. Experimental and clinical studies on AMCA, the antifibrinolytically active isomer of p-aminomethyl cyclohexane carboxylic acid. Scand J Haematol. 1965; 2: 230-247.

16. Dubber AH, McNicol GP, Douglas AS, Melander B. Some properties of the antifibrinolytically active isomer of aminomethylcyclohexane carboxylic acid. Lancet 1964; II, 1317

17. Carter G, Goss A. Tranexamic acid mouthwash: a prospective randomized study of a 2-day regimen vs 5 -day regimen to prevent postoperative bleeding in anticoagulated patients requiring dental extractions. Int Oral Maxillofac Surg. 2003; 32: 504-507.

18. Sindet-Pedersen S, Ramström G, Bernvil S, Blombäck M. Hemostatic effect of tranexamic acid mouthwash in anticoagulant-treated patients undergoing oral surgery. N Engl J Med. 1989; 320: 840-843.

19. Chan CC, Chan YY, Tanweer F. Systematic review and meta-analysis of the use of tranexamic acid in tonsillectomy. Eur Arch Otorhinolaryngol. 2013; 270: 735-748.

20. Coker N, Higgins DJ. Tranexamic acid applied topically to achieve haemostasis. Anaesthesia. 2000; 55: 600-601.

21. RevMan 2011 - The Nordic Cochrane
Centre, The Cochrane Collaboration. Review Manager (RevMan). 5.1. Copenhagen: The Nordic Cochrane Centre, The Cochrane Collaboration, 2011.

22. Higgins JPT, Green S. (editors). Cochrane Handbook for Systematic Reviews of Interventions Version 5.1.0 [updated March 2011]. The Cochrane Collaboration, 2011. Available from www.cochrane-handbook. org.

23. Clarke M., Horton R. Bringing it all together: Lancet-Cochrane collaborate on systematic reviews. Lancet. 2001; 357: 1728.

24. Moher D, Cook DJ, Eastwood S, Olkin I, Rennie D, Stroup DF for the QUOROM Group; Improving the quality of reports of meta-analyses of randomised controlled trials: the QUOROM statement. Lancet. 1999; 354: 1896-1900

25. DerSimonian R., Laird N. Meta-analysis in clinical trials. Control Clin Trials. 1986; 7 : 177-188.

26. Mantel N., Haenszel W. Statistical aspects of the analysis of data from retrospective studies of disease. J Natl Cancer Inst. 1959; 22: 719-748.

27. Higgins JPT, Thompson SG. Quantifying heterogeneity in a meta-analysis. Statist Med. 2002; 21: 1539-1558.

28. Higgins JPT, Deeks JJ, Altman DG on behalf of the Cochrane Statistical Methods Group; Chapter 16: Special topics in statistics (2008) The Cochrane Collaboration. John Wiley \& Sons, Ltd "The Cochrane Book Series".

29. Hozo SP, Djulbegovic B, Hozo I. Estimating the mean and variance from the median, range, and the size of a sample. BMC Med Res Methodol. 2005; 20: 5-13.

30. Abbasi H, Behdad S, Ayatollahi V, Nazemian $\mathrm{N}$, Mirshamsi P. Comparison of two doses of tranexamic acid on bleeding and surgery site quality during sinus endoscopy surgery. Adv Clin Exp Med. 2012; 21: 773-780.

31. Yaniv E, Shvero J, Hadar T. Hemostatic effect of tranexamic acid in elective nasal surgery. Am J Rhinol. 2006; 20: 227-229.

32. Alimian M, Mohseni M. The effect of intravenous tranexamic acid on blood loss and surgical field quality during endoscopic sinus surgery: a placebo-controlled clinical trial. J Clin Anest; 2011::23: 611-615.

33. Athanasiadis $T$, Beule AG, Wormald PJ. Effects of topical antifibrinolytics in endoscopic sinus surgery: a pilot randomized controlled trial. Am J Rhinol. 2007; 21: 737742.

34. Chhapola S, Matta I. Short-term use of tranexamic acid to reduce blood loss in endoscopic nasal surgeries. Clin Rhinol. 2011; 4: 79-81.

35. Jabalameli M, Zakeri K. Evaluation of topical tranexamic acid on intraoperative bleeding in endoscopic sinus surgery. Iran J Med Sci. 2006; 31: 221-223.

36. Langille MA, Chiarella A, Côté DW. Intravenous tranexamic acid and intraoperative visualization during functional endoscopic sinus surgery: a double-blind randomized controlled trial. Int Forum Allergy
Rhinol. 2013; 3: 315-318

37. Boezaart AP, van der Merwe J, Coetzee A. Comparison of sodium nitroprusside- and esmolol-induced controlled hypotension for functional endoscopic sinus surgery. Can J Anaesth. 1995; 42: 373-376.

38. Fodstad H, Liliequist B. Spontaneous thrombosis of ruptured intracranial aneurysms during treatment with tranexamic acid (AMCA): report of three cases. Acta Neurochir Wien 1979; 49: 129-144.

39. Rydin E, Lundberg PO. Tranexamic acid and intracranial thrombosis. Lancet. 1976; 2 (7975): 49.

40. Davies D, Howell DA. Tranexamic acid and arterial thrombosis [letter]. Lancet. 1977; 1(8001): 49.

41. Albronda T, Gökemeyer JDM, vanHaeften TW. Transient acute renal failure due to tranexamic acid therapy for diffuse intravascular coagulation. Neth J Med. 1991; 39: 127-128.

42. Fernández Lucas $M$, Liaño $F$, Navarro JF, Sastre JL, Quereda C, Ortuño J, et al. Acute renal failure secondary to antifibrinolytic therapy. Nephron. 1995; 69: 478-479.

43. Horrow JC, Van Riper DF, Strong MD, Grunewald KE, Parmet JL, et al. The doseresponse relationship of tranexamic acid. Anesthesiology 1995; 82: 383-92

44. Coffey A, Pittmam J, Halbrook H, Fehrenbacher J, Beckman D, Hormuth D, et al. The use of tranexamic acid to reduce postoperative bleeding following cardiac surgery: a double-blind randomized trial. Am Surg. 1995; 61: 566-568.

45. Horrow JC, Van Riper DF, StrongMD, Brodsky I, Parmet JL. Hemostatic effects of tranexamic acid and desmopressin during cardiac surgery. Circulation. 1991; 84: 20632070.

46. Speekenbrink RGH, Vonk ABA, Wildevuur $\mathrm{CRH}$, Eijsman L. Hemostatic efficacy of dipyridamole, tranexamic acid, and aprotinin in coronary bypass grafting. Ann Thorac Surg. 1995; 59: 438-442.

47. Lindoff C, Rybo G, Åstedt B. Treatment with tranexamic acid during pregnancy, and the risk of thrombo-embolic complications. Thromb Haemostb. 1993; 70: 238-240.

Vishal Pundir

Speciality Doctor, Otorhinolaryngo-

logy

East Sussex Healthcare NHS Trust

Conquest Hospital

The Ridge, St.Leonards-on-Sea

East Sussex TN37 7RD

United Kingdom

Tel: +44-7956672723

E-mail: vishalpundir@yahoo.com 